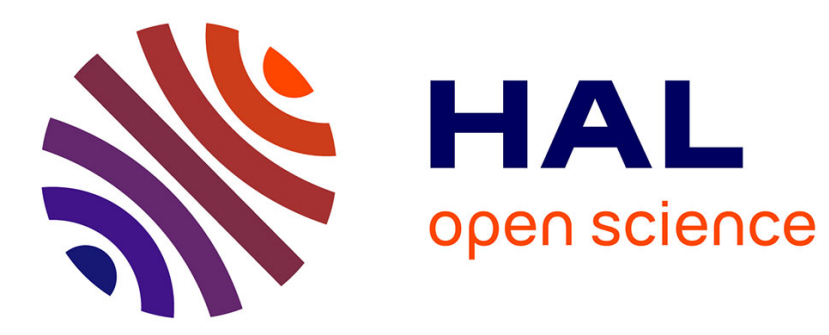

\title{
Barrier height distribution and dipolar relaxation in metal-insulator-semiconductor junctions with molecular insulator: Ageing effects
}

\author{
Alain-Bruno Fadjie-Djomkam, Soraya Ababou-Girard, Christian Godet
}

\section{- To cite this version:}

Alain-Bruno Fadjie-Djomkam, Soraya Ababou-Girard, Christian Godet. Barrier height distribution and dipolar relaxation in metal-insulator-semiconductor junctions with molecular insulator: Ageing effects. Journal of Applied Physics, 2012, 112, pp.113701-1-113701-11. 10.1063/1.4767121 . hal01121392

\section{HAL Id: hal-01121392 \\ https://hal.science/hal-01121392}

Submitted on 5 Mar 2015

HAL is a multi-disciplinary open access archive for the deposit and dissemination of scientific research documents, whether they are published or not. The documents may come from teaching and research institutions in France or abroad, or from public or private research centers.
L'archive ouverte pluridisciplinaire HAL, est destinée au dépôt et à la diffusion de documents scientifiques de niveau recherche, publiés ou non, émanant des établissements d'enseignement et de recherche français ou étrangers, des laboratoires publics ou privés. 
AIP Applied Physics

\title{
Barrier height distribution and dipolar relaxation in metal-insulator- semiconductor junctions with molecular insulator: Ageing effects
}

\author{
A. B. Fadjie-Djomkam, S. Ababou-Girard, and C. Godet
}

Citation: J. Appl. Phys. 112, 113701 (2012); doi: 10.1063/1.4767121

View online: http://dx.doi.org/10.1063/1.4767121

View Table of Contents: http://jap.aip.org/resource/1/JAPIAU/v112/i11

Published by the American Institute of Physics.

\section{Related Articles}

Atomic layer deposition of $\mathrm{Al} 2 \mathrm{O} 3$ on GaSb using in situ hydrogen plasma exposure

Appl. Phys. Lett. 101, 231601 (2012)

Defect induced mobility enhancement: Gadolinium oxide (100) on Si(100)

Appl. Phys. Lett. 101, 222903 (2012)

Band alignment in $\mathrm{Ge} / \mathrm{GeO} / \mathrm{HfO} 2 / \mathrm{TiO} 2$ heterojunctions as measured by hard x-ray photoelectron spectroscopy Appl. Phys. Lett. 101, 222110 (2012)

Electronic properties at the oxide interface with silicon and germanium through $\mathrm{x}$-ray induced oxide charging Appl. Phys. Lett. 101, 211606 (2012)

A computational study of graphene silicon contact

J. Appl. Phys. 112, 104502 (2012)

\section{Additional information on J. Appl. Phys.}

Journal Homepage: http://jap.aip.org/

Journal Information: http://jap.aip.org/about/about_the_journal

Top downloads: http://jap.aip.org/features/most_downloaded

Information for Authors: http://jap.aip.org/authors

\section{ADVERTISEMENT}

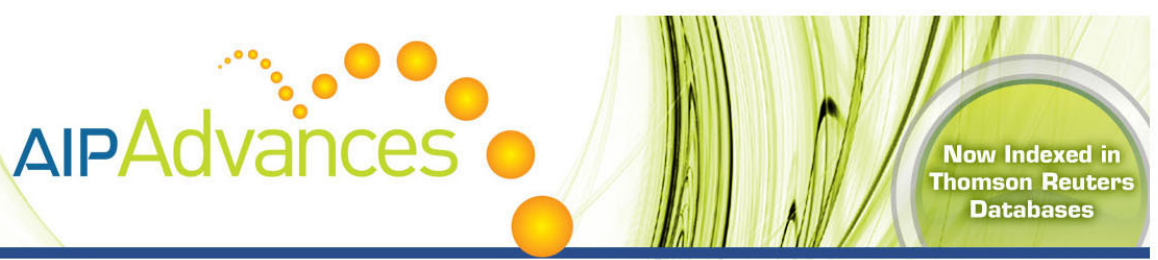

\section{Explore AIP's open access journal: •Rapid publication \\ - Article-level metrics \\ Post-publication rating and commenting}




\title{
Barrier height distribution and dipolar relaxation in metal-insulator-semiconductor junctions with molecular insulator: Ageing effects
}

\author{
A. B. Fadjie-Djomkam, S. Ababou-Girard, and C. Godet ${ }^{\text {a) }}$ \\ Institut de Physique de Rennes, CNRS UMR 6251, Université de Rennes 1, Campus de Beaulieu, \\ 35042 Rennes Cedex, France
}

(Received 11 July 2012; accepted 26 October 2012; published online 3 December 2012)

\begin{abstract}
Electrical transport through molecular monolayers being very sensitive to disorder effects, admittance and current density characteristics of $\mathrm{Hg} / / \mathrm{C}_{12} \mathrm{H}_{25}-n \mathrm{Si}$ junctions incorporating covalently bonded $n$-alkyl molecular layers, were investigated at low temperature $(150-300 \mathrm{~K})$, in the as-grafted state and after ageing at the ambient. This comparison reveals local oxidation effects both at the submicron scale in the effective barrier height distribution and at the molecular scale in the dipolar relaxation. In the bias range dominated by thermionic emission and modified by the tunnel barrier $(\mathrm{TB})$ attenuation, $\exp \left(-\beta^{0} d_{\mathrm{T}}\right)$, where $d_{\mathrm{T}}$ is the thickness of the molecular tunnel barrier and $\beta^{0}$ is the inverse attenuation length at zero applied bias, some excess current is attributed to a distribution of low barrier height patches. Complementary methods are used to analyze the current density $J(V, T)$ characteristics of metal-insulator-semiconductor tunnel diodes. Assuming a Gaussian distribution of barrier heights centered at $q \Phi_{\mathrm{B}}$ provides an analytical expression of the effective barrier height, $q \Phi_{\mathrm{EFF}}(T)=q \Phi_{\mathrm{B}}+(k T) \beta^{0} d_{\mathrm{T}}-(q \delta \Phi)^{2} / 2 k T$; this allows fitting of the distribution standard deviation $\delta \Phi$ and tunnel parameter $\left(\beta^{0} d_{\mathrm{T}}\right)$ over a wide temperature range. In a more realistic modeling including the voltage dependence of barrier height and circular patch area, the so-called "pinch-off" effect is described by a distribution of parameter $\gamma=3\left(\Delta_{P} R_{P}^{2} / 4\right)^{1 / 3}$, which combines interface potential modulation and patch area variations. An arbitrary distribution of $\gamma$ values, fitted to low-temperature $J(V)$ data, is equally well described by Gaussian or exponential functions. Ageing in air also increases the interface oxidation of Si substrate and affects the density of localized states near mid gap, which typically rises to the high $10^{11} \mathrm{eV}^{-1} \mathrm{~cm}^{-2}$ range, as compared with $D_{\mathrm{S}}<10^{11} \mathrm{eV}^{-1} \mathrm{~cm}^{-2}$ in the as-grafted state. The bias-independent relaxation observed near $1 \mathrm{kHz}$ at low temperature may be attributed either to dipoles in the alkyl chain induced by the strong permanent dipoles of interface silicon oxide or to a local relaxation of water molecules trapped at the $\mathrm{OML} / \mathrm{silicon}$ interface. The respective roles of $\mathrm{SiO}_{2}$ formation and water physisorption on the decrease of patch barrier height are also discussed. (C) 2012 American Institute of Physics. [http://dx.doi.org/10.1063/1.4767121]
\end{abstract}

\section{INTRODUCTION}

The development of metal-insulator-semiconductor (MIS) junctions with ultra-thin insulator $\left(d_{\mathrm{T}}<3 \mathrm{~nm}\right)$ has stimulated the study of new insulating materials, such as high band gap saturated organic molecules (e.g., $n$-alkyl molecules). ${ }^{1-6}$ In the last two decades, important progress has been made in the controlled covalent grafting of molecular monolayers on semiconductors. $^{7-10}$

The organization of linear molecules in quasi-2D assemblies is the result of a delicate interplay between substrateadsorbate interactions and lateral intermolecular (electrostatic, van der Waals) interactions. ${ }^{11,12}$ Strong covalent grafting produces robust assemblies, however irreversible binding to the semiconductor substrate may lead to substantial fluctuations in molecular packing density and formation of domains with variable average orientation. ${ }^{1,13,14}$

\footnotetext{
a) Author to whom correspondence should be addressed. Electronic mail: christian.godet@univ-rennes1.fr. Tel.: +332232357 06. Fax: +33223 2361 98. Present address: EPSI-IPR (Bât. 11C-Beaulieu), Université Rennes 1, 35042 RENNES, France.
}

In spite of the intrinsic topological disorder of organic monolayers (OML) covalently bound to semiconductor (SC) surfaces, electrical transport properties of such M-OML-SC devices have been widely studied ${ }^{15-37}$ due to their relatively low density of electrically active defects at the OML-Si interface, at least in their as-grown state. ${ }^{28,32,34,38-42}$ Linear saturated (n-alkyl) chains play the role of a nanometer-thick tunnel barrier (TB); however steric molecular constraints do not allow a full passivation of $\mathrm{Si}(111)$ surface sites, which remain subject to post-grafting oxidation at the ambient. ${ }^{43-49}$ Substrate oxidation due to oxygen molecule penetration through the OML occurs at increasing rates with decreasing chain length, indicating increasingly poor organization or porosity of the alkyl chains layer. ${ }^{12}$ Preferential post-grafting oxidation (Fig. 1) is expected at specific areas with either lower molecular coverage or higher molecular disorder; hence, physically adsorbed oxygen-containing species can be trapped within the organic film or bound to the pinholes. ${ }^{49}$

As a consequence, a large dispersion in electrical properties of the corresponding devices is expected and has been observed. ${ }^{19,35-37}$ In the particular case of macroscopic 


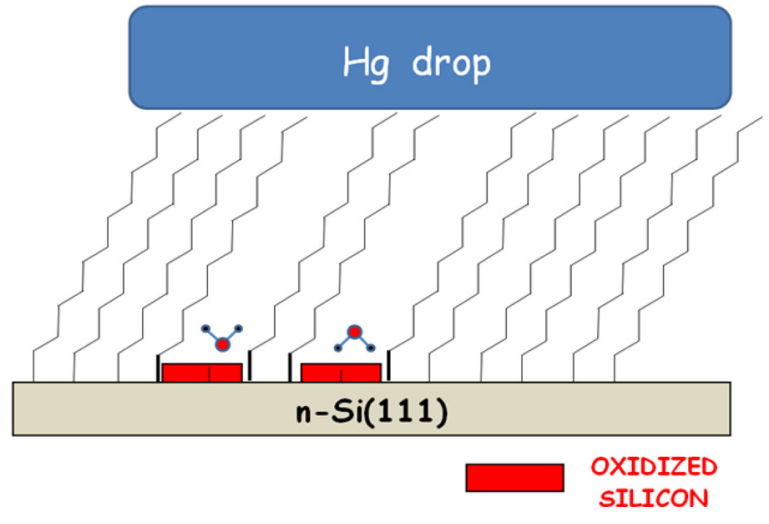

FIG. 1. Schematic $\mathrm{C}_{12} \mathrm{H}_{25}-n$-Si assembly after ageing describing surface oxidation at specific regions with low molecular coverage, along with preferential water molecule adsorption.

(mm size) molecular junctions obtained by covalent bonding of a nanometer-thick molecular monolayer to a semiconducting substrate, different sources of fluctuations with possible influence on transport properties have been reviewed. They include: (i) upper electrode non uniformity including formation of conducting filaments through the insulating layer; ${ }^{17}$ (ii) non uniformity in OML thickness resulting from low coverage, poor organization, and variable tilt angle of the molecular layer; ${ }^{19,35}$ (iii) spatial dependence of some induced density of states in the molecular layer band gap due to the strong covalent bonding with underlying metal or semiconductor; ${ }^{20,27}$ (iv) fluctuation of flat-band voltage ${ }^{24}$ due to spatial dependence of either top electrode work function (e.g., due to metal oxidation), or Si electron affinity (e.g., due to semiconductor oxidation), or else molecular dipole density; (v) non uniform oxidation of the bottom metal or semiconductor creating interface traps which can be detected by specific trap assisted tunneling signature in noise dynamics or in $\mathrm{C}-\mathrm{V}$ characteristics; ${ }^{21,28,32-34}$ (vi) redox effects consisting in charge transfer ${ }^{33,50}$ from the semiconductor to the adventitious water layer which is present on any surface at the ambient, with some preferential water physisorption being expected on oxidized hydrophilic regions.

This work addresses the role of monolayer quality through a comparison of the temperature dependence of electron transport over a wide temperature range, before and after ageing in air. Hence, non uniformity in OML thickness (problem (ii)) and induced density of states (problem (iii)) are not expected to be strongly affected by the ageing process, since X-ray photoelectron spectroscopy (XPS) gives evidence of constant alkyl molecule coverage. Furthermore, problem (i) can be discarded due to the high surface energy of $\mathrm{Hg}$ (top electrode). ${ }^{19}$

In contrast, a broadening of the distribution of potential barrier fluctuations can be expected after ageing, as a result of preferential oxidation of silicon substrate in areas with smaller alkyl molecule coverage or increased disorder in the molecular packing. In addition, hydrophilic silicon oxide regions may also favor the physisorption of polar water molecules and contribute to modify the interface potential. ${ }^{51}$ In order to get some insight in the dynamics of the molecular monolayer $/ \mathrm{SiO}_{2} / \mathrm{Si}$ system, this work investigates the dipolar relaxation signature of chemisorbed and physisorbed polar moieties over a broad electrical bias and temperature range.
Most of previous current-voltage $(I-V)$ characteristics of molecular MIS tunnel junctions (M-OML-SC) have been analyzed assuming homogeneous barrier height over a macroscopic contact area (typically a few $10^{-3} \mathrm{~cm}^{2}$ ). For example, in a previous work, we have investigated the voltage partition in a rectifying $\mathrm{Hg} / / \mathrm{C}_{12} \mathrm{H}_{25}-n \mathrm{Si}(111)$ tunnel junction in the forward bias regime. Rather than using "nominally identical" junctions with variable chain length $\left(d_{\mathrm{T}}\right)$, the tunnel barrier attenuation, $\exp \left(-\beta^{0} d_{\mathrm{T}}\right)$, was derived from the temperature dependence of the apparent saturation current or effective barrier height

$$
q \Phi_{\mathrm{EFF}}(T)=q \Phi_{\mathrm{B}}+(k T) \beta^{0} d_{\mathrm{T}}
$$

in the thermionic emission (TE) regime. ${ }^{32}$ Such hypothesis may be reasonable near room temperature, but clear indications of some excess current, as compared with the theoretical thermionic current with a single barrier height, are observed at low applied bias and low temperatures.

Such excess current resulting from non-uniform Schottky contacts has extensively been reported in electronic device literature. ${ }^{52-64}$ A realistic model for calculating $(I-V)$ characteristics considers a distribution of low barrier height patches $\left(q \Phi_{\mathrm{B}}^{H O M}-\Delta_{P}\right)$ embedded in an extended region of homogeneous but larger barrier heights $\left(q \Phi_{\mathrm{B}}^{H O M}\right)$. When the Schottky barrier height varies with large amplitudes on small lateral length scale, the conduction path in front of a patch with low barrier height is partially blocked by the presence of high barrier height patches in its close proximity. When this "pinch off" occurs, the potential at a "saddle point" in front of the low barrier height patch determines the transport properties. The condition for "pinch off," $\frac{\Delta_{P}}{V_{\mathrm{bb}}}>\frac{2 R_{P}}{W}$, is obtained from the potential profile equation, where $V_{\mathrm{bb}}$ is the total band bending, $W$ is the width of the space charge layer, $R_{P}$ is the patch radius, and $\left(q \Phi_{\mathrm{B}}^{H O M}-\Delta_{P}\right)$ is the potential right at the interface.

Accurate modeling should include this so-called "pinchoff" effect, by taking into account the voltage dependence of both barrier height at the saddle point and effective patch area. ${ }^{54,55,59,60}$ In the dipole approximation, valid for a circular patch radius $R_{P}$ smaller than the width of the space charge layer, $W$, the local barrier height

$$
q \Phi_{\mathrm{B}}^{S A D}=q \Phi_{\mathrm{B}}^{H O M}-3 q V_{\mathrm{bb}}\left(\frac{\Delta_{P} R_{P}^{2}}{2 V_{\mathrm{bb}} W^{2}}\right)^{1 / 3},
$$

is thus intermediate between the values $q \Phi_{\mathrm{B}}^{H O M}$ of the surrounding homogeneous area and $\left(q \Phi_{\mathrm{B}}^{H O M}-\Delta_{P}\right)$ of the patch right at the interface. ${ }^{54,55,59,60}$ For a circular patch, the current is thus governed by the interface band bending, $V_{\mathrm{bb}}$, and the patch parameter $\gamma=3\left(\Delta_{P} R_{P}^{2} / 4\right)^{1 / 3}$. Note that the term related to the tunnel attenuation, $(k T) \beta^{0} d_{\mathrm{T}}$ in Eq. (1), is assumed to be independent of the patch barrier height.

As will be shown in Sec. III, a wide temperature range is crucial to assess the role of inhomogeneous barrier height distribution on the transport characteristics of tunnel MIS diodes. Hence, admittance and current density characteristics of $\mathrm{Hg} / / \mathrm{C}_{12} \mathrm{H}_{25}-n \mathrm{Si}$ junctions were characterized either in their as-grown state or after ageing at the ambient, and the 
measurement temperature range was extended to $153 \mathrm{~K}$, well below the $\mathrm{Hg}$ freezing temperature $(234 \mathrm{~K})$ as compared with previous studies on similar molecular devices. ${ }^{32}$ Oxidation effects at the Si/OML interface are used to emphasize the role of imperfections in the monolayer organization; dc and ac electrical transport characteristics reveal local oxidation effects both at the submicron scale (effective barrier height distribution and average density of electronic states localized at the Si/OML interface) and at the molecular scale in the dipolar relaxation dynamics.

Section II describes the experimental methods, including XPS characterization of OML coverage and surface oxidation, dc and ac electrical transport. Section III reports the current density $J(V, T)$ and admittance $Y(V, T, \omega)$ characteristics measured as a function of temperature, $T$, and dc voltage, $V$; admittance is measured in a wide frequency range $\left(3 \times 10^{-2}\right.$ to $10^{7} \mathrm{~Hz}$ ) in order to investigate the dynamic characteristics of the tunnel barrier, the space charge region, the interface traps, and the relaxation of dipoles at the molecular scale.

In Sec. IV, lateral interface potential inhomogeneities in $\mathrm{Hg} / / \mathrm{C}_{12} \mathrm{H}_{25}-n \mathrm{Si}(111)$ junctions will be described quantitatively using two complementary methods for the analysis of dc current density $J(V, T)$ characteristics: (i) Model A assumes a Gaussian distribution of Schottky barrier height values and neglects any "pinch-off" effect: this rough approximation provides an analytical $T$-dependence of the effective barrier height (Eq. (1) is thus modified) giving the homogeneous thermionic emission barrier height, $q \Phi_{\mathrm{B}}^{H O M}$, and distribution width; (ii) Model B includes the "pinch-off" effect: the homogeneous thermionic emission barrier height, $q \Phi_{\mathrm{B}}^{H O M}$, and an arbitrary distribution $\rho_{i}\left(\gamma_{i}\right)$ of $\gamma$ values across the contact area can be derived from fitting a low-temperature $J(V)$ characteristics; the shape (exponential or Gaussian) and width of the $\rho_{i}\left(\gamma_{i}\right)$ distribution are discussed for the aged junction, in relation with the flat band voltage and the bias-dependence of the apparent ideality factor in $J(V, T)$ data.

In Sec. $\mathrm{V}$, the admittance measurements are compared with the theoretical response of a non equilibrium tunnel junction including the density of electrically active interface defects. ${ }^{34,65,66}$ The physical origin of some bias-independent dipolar relaxation observed at low temperature is also addressed in relation with interface oxide and possible water physisorption effects.

\section{EXPERIMENTAL}

Covalent grafting of linear alkene molecules on hydrogenated $\mathrm{Si}(111): \mathrm{H}$ surfaces using a UV-assisted liquid phase process was described previously. ${ }^{32}$ A low-doped $n$-type Si ( $\rho_{S}=1-10 \Omega \mathrm{cm}$, Siltronix) has been chosen to obtain rectifying junctions. ${ }^{18,23}$ The $\mathrm{Hg} / / \mathrm{C}_{12} \mathrm{H}_{25}-n \mathrm{Si}(111)$ junctions were characterized in the as-grafted state and after long term ageing at the ambient for 18 months. The $\mathrm{C}_{12} \mathrm{H}_{25}-n \mathrm{Si}(111)$ surface was characterized by XPS immediately before dc and ac electrical transport measurements.

\section{A. X-ray photoelectron spectroscopy}

The alkyl molecular coverage $\left(\Sigma_{\mathrm{OML}}\right)$ and silicon oxidation were characterized by XPS after a few minutes exposure to the ambient and after ageing, using a $\mathrm{Mg} \mathrm{K} \alpha(1253.6 \mathrm{eV})$ anode source and Omicron HA100 electron energy analyser (1.0 eV resolution). The thickness, $d_{O M L}$, of the molecular layer immobilized on the $\mathrm{Si}$ surface was derived from the attenuation $[\mathrm{Si} 2 \mathrm{p}]_{\text {grafted }} /[\mathrm{Si} 2 \mathrm{p}]_{\text {bare }}=\exp \left(-d_{O M L} / \lambda_{O M L} \cos \alpha\right)$, with an inelastic mean free path value $\lambda_{O M L}=3.5 \mathrm{~nm}$ (for $\mathrm{Si} 2 \mathrm{p}$ photoelectrons) typical of a dense molecular layer. ${ }^{67,68}$ After ageing, the oxide thickness, $d_{O X}$, was derived from the relative intensities of the $\mathrm{Si} 2 \mathrm{p}$ bands at $103 \mathrm{eV}\left(\mathrm{SiO}_{2}\right)$ and $99 \mathrm{eV}(\mathrm{Si})$ binding energies, assuming a homogeneous coverage of the $\mathrm{Si}$ substrate and using $\left(d_{\mathrm{OX}} / L_{\mathrm{SiO} 2} \cos \alpha\right)=\mathrm{Ln}$ $\left[1+R_{0}{ }^{-1}\left([\mathrm{Si} 2 \mathrm{p}]_{\mathrm{SiO} 2} /[\mathrm{Si} 2 \mathrm{p}]_{\mathrm{Si}}\right)\right]$ with $R_{0}=0.76 \pm 0.2$ and an attenuation length $L_{\mathrm{SiO} 2}=2.923 \mathrm{~nm}$ in silicon oxide for a $\mathrm{Mg}$ K $\alpha$ source. ${ }^{69}$

\section{B. Electrical transport measurements}

Surfaces modified by a molecular monolayer were probed using a mercury top electrode (contact area $S=5 \times 10^{-3} \mathrm{~cm}^{2}$ ) to avoid electrical shorts through possible pinholes in the OML. A parallel plate home-made Teflon cell, compatible with $\mathrm{Hg}$, was used for current density $J(V, T)$ and admittance $Y(V, T, \omega)$ measurements, as described previously. ${ }^{32}$ The cell was placed in a cryostat under dry nitrogen flow to avoid water condensation and to minimize surface oxidation during measurements. A solid $\mathrm{Hg}$ electrode is obtained in the low temperature range $(153 \mathrm{~K}<T<234 \mathrm{~K})$ useful to assess the role of inhomogeneous barrier height distribution in the transport characteristics of $\mathrm{Hg} / / \mathrm{C}_{12} \mathrm{H}_{25}-n \mathrm{Si}$ junctions.

The top contact to the OML was taken through a Pt wire and a fresh $\mathrm{Hg}$ drop (99.999\% Fluka), and an ohmic back contact was obtained by applying Ag paste on the scratched Si backside. A Keithley 6487 picoammeter was used for $J(V)$ data acquisition using alternatively positive and negative polarities. Admittance measurements were carried out with a frequency response analyzer (Alpha-A High Resolution measurement system, Novocontrol Technologies) in two runs $\left(V_{\mathrm{AC}}=10 \mathrm{mV}\right)$ : a voltage sweep (step $\left.25 \mathrm{mV}\right)$ and a frequency sweep (range $3 \times 10^{-2} \mathrm{~Hz}$ to $1 \times 10^{7} \mathrm{~Hz}$ ), to study the measured complex admittance, $Y(V, T, \omega)=G_{\mathrm{m}}+\mathrm{j} \omega C_{\mathrm{m}}$, against voltage, $V$, and frequency, $\omega / 2 \pi$. The Teflon cell capacitance $\left(C_{\mathrm{PAR}}=4.9 \mathrm{pF}\right)$ was subtracted to obtain $C_{\mathrm{m}}$. At each temperature, the series resistance $R_{\mathrm{S}}$ can be derived from the high frequency value of the real part of the impedance, $R_{\mathrm{S}}=G_{\mathrm{m}} /\left(G_{\mathrm{m}}{ }^{2}+\omega^{2} C_{\mathrm{m}}{ }^{2}\right){ }^{70}$ Tunnel junction electrical response and dipolar relaxation of molecular moieties were tentatively discriminated using the temperature and bias dependence of their respective characteristic frequencies.

\section{RESULTS}

The optical thickness $d_{\mathrm{OML}}=1.45 \mathrm{~nm}$ is consistent with previous reports and with the length of the $\mathrm{C}_{12} n$-alkyl molecule, including some tilt-angle of about $30^{\circ} .{ }^{10} \mathrm{We}$ will show that, although the molecular coverage is not optimized, ${ }^{71} \mathrm{dc}$ electrical characteristics are fully consistent with devicequality junctions reported in previous work. We have chosen a device representative of the average of the conductance distribution in order to observe chemical and electrical changes brought by long term (18 months) ageing in ambient air. 


\section{A. Surface oxidation}

Immediately after dodecyl grafting, no $\mathrm{SiO}_{2}$ component could be observed near $103 \mathrm{eV}$ on Si2p spectra taken at an emission angle $\alpha=45^{\circ}$ (Fig. 2(a)). Considering some uncertainty in the Si2p peak baseline, an upper limit of $\Sigma_{\mathrm{SiO} 2} \approx 1 \times 10^{14} \mathrm{~cm}^{-2}(0.05 \mathrm{~nm})$ can be estimated for the asgrafted $\mathrm{C}_{12} \mathrm{H}_{25}-n \mathrm{Si}$ assembly before ageing. The optical thickness $d_{\mathrm{OML}}=1.45 \mathrm{~nm}$ and the molecular coverage $\Sigma_{\mathrm{OML}}=2.3 \times 10^{14} \mathrm{~cm}^{-2}$ both indicate grafting of a rather dense $\mathrm{C}_{12}$ monolayer. After 18 months ageing at the ambient, a strong $\mathrm{SiO}_{2}$ component is observed near $103 \mathrm{eV}$ binding energy (BE) (Fig. 2(a), inset), corresponding to $0.17 \mathrm{~nm}$ of $\mathrm{SiO}_{2}\left(2.3 \mathrm{~g} . \mathrm{cm}^{-3}\right)$, which represents an average surface density, $\Sigma_{\mathrm{SiO} 2}=4 \times 10^{14} \mathrm{~cm}^{-2}$, i.e., about half a monolayer of oxidized $\mathrm{Si}^{4+}$ atoms. The alkyl molecular coverage remains unchanged after ageing, as shown by similar values of the ratio of $\mathrm{C} 1 \mathrm{~s}$ to $\mathrm{Si} 2 \mathrm{p}$ intensities before $(0.78)$ and after (0.75) ageing.

Considering the well-known overlap of O1s bands which result from different chemical environments, decomposition of the broad unstructured O1s peak (Fig. 2(b)) would be somewhat arbitrary; in contrast with previous analysis, ${ }^{33}$ at least three components $\left(\mathrm{SiO}_{2}, \mathrm{OH}, \mathrm{H}_{2} \mathrm{O}\right)$ are expected for an accurate decomposition of $\mathrm{O} 1 \mathrm{~s}$ spectra of the $\mathrm{OML} / \mathrm{SiO}_{2} / \mathrm{Si}$ system. In this context, a comparison of XPS spectra before and after ageing is very helpful. Since no $\mathrm{SiO}_{2}$
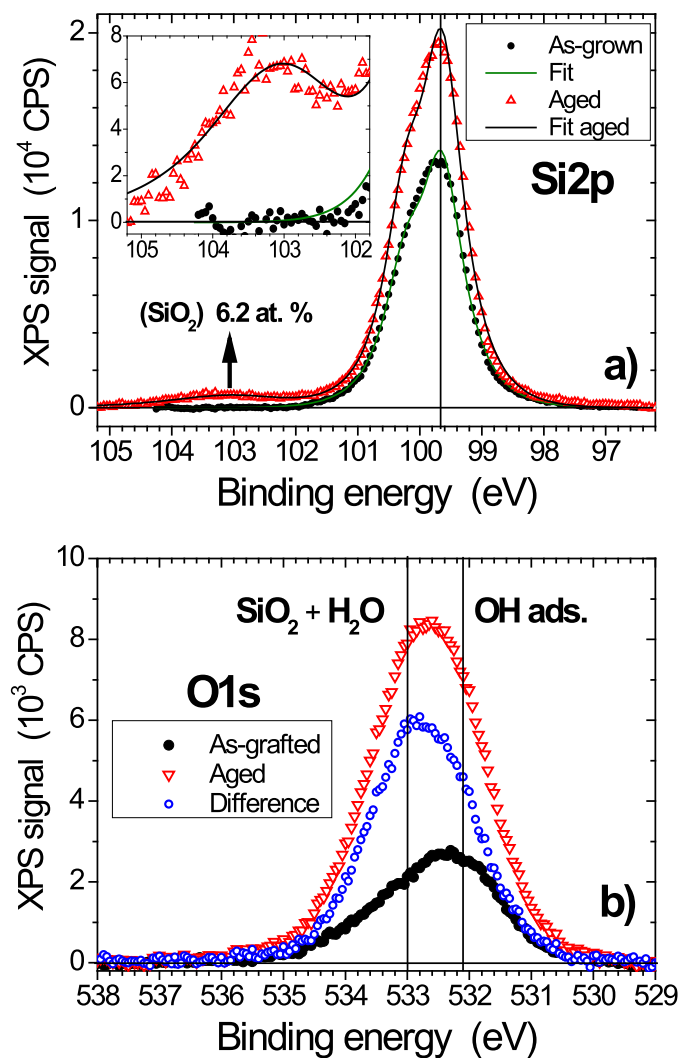

FIG. 2. XPS spectra $\left(\alpha=45^{\circ}\right)$ of a $\mathrm{C}_{12} \mathrm{H}_{25}-n$-Si surface in the as-grafted state and after ageing at the ambient (18 months): (a) Si 2p core level, (b) $\mathrm{O} 1 \mathrm{~s}$ core level. The oxide component at $103.0 \mathrm{eV}$ represents 6.2 at. $\%$ of the total $\mathrm{Si} 2 \mathrm{p}$ intensity. The main component appears at $533.0 \mathrm{eV}\left(\mathrm{H}_{2} \mathrm{O}\right.$ and $\mathrm{SiO}_{2}$ ) in the $\mathrm{O} 1 \mathrm{~s}$ difference spectrum, with a shoulder at $532.1 \mathrm{eV}$ (adventitious adsorbed $\mathrm{OH}$ ) is observed in the Si2p core level of the as-grafted state, the peak at a binding energy of $532.4 \mathrm{eV}$ is attributed to adventitious adsorbed $\mathrm{OH}$ species. ${ }^{72}$ After ageing, the $\mathrm{O} 1 \mathrm{~s}$ peak maximum shifts to higher binding energy; the difference spectrum (circles in Fig. 2(b)) reveals an increase of the low $\mathrm{BE}$ component (shoulder at $532.1 \mathrm{eV}$ ) and a new component at $533.0 \mathrm{eV}$, which is attributed to both interface oxide $\left(\mathrm{SiO}_{2}\right)^{73,74}$ and possibly water molecules, ${ }^{72,75}$ which can be more strongly adsorbed than the dioxygen molecule. The total O1s signal intensity is larger than the amount expected from a $\mathrm{SiO}_{2}$ stoichiometry for the interfacial oxide alone, by a factor of 1.7; neglecting the attenuation by the molecular layer, the amount of adventitious adsorbed $\mathrm{OH}$ and $\mathrm{H}_{2} \mathrm{O}$ molecules is thus comparable to the surface density of oxidized Si atoms.

\section{B. DC electrical transport}

Since transport properties of molecular junctions are extremely sensitive to molecular monolayer quality, the distribution of conductance in either reverse or forward bias regimes may give some indication about the dominant source of inhomogeneity. ${ }^{19,35-37}$ Figure 3 (inset) shows the distribution of conductance, $G=\mathrm{d} J / \mathrm{d} V$, values measured in reverse bias $(0 \mathrm{~V})$ and forward bias $(+1 \mathrm{~V})$ regimes, for fresh $\mathrm{C}_{12}$ junctions prepared in nominally identical conditions. The average values and typical distribution over one decade found for $G$ (rev.) $=0.8-10 \times 10^{-7} \Omega^{-1} \mathrm{~cm}^{-2}$ and $G$ (fwd.) $=0.07$ $0.7 \Omega^{-1} \mathrm{~cm}^{-2}$ are fully consistent with device-quality junctions reported in previous work.

For this comparative analysis of local oxidation effects in the effective barrier height distribution, before and after ageing, we have chosen a device representative of the average of the conductance distribution (Figs. 3 and 4). Measurements were performed successively at points A (immediately after XPS analysis) and B (one week later), to check for data repeatability.

Details of the current density $J(V, T)$ characteristics of the $\mathrm{Hg} / / \mathrm{C}_{12} \mathrm{H}_{25}-n \mathrm{Si}(111)$ junction in the as-grafted state were reported previously, ${ }^{32}$ including the strong rectification

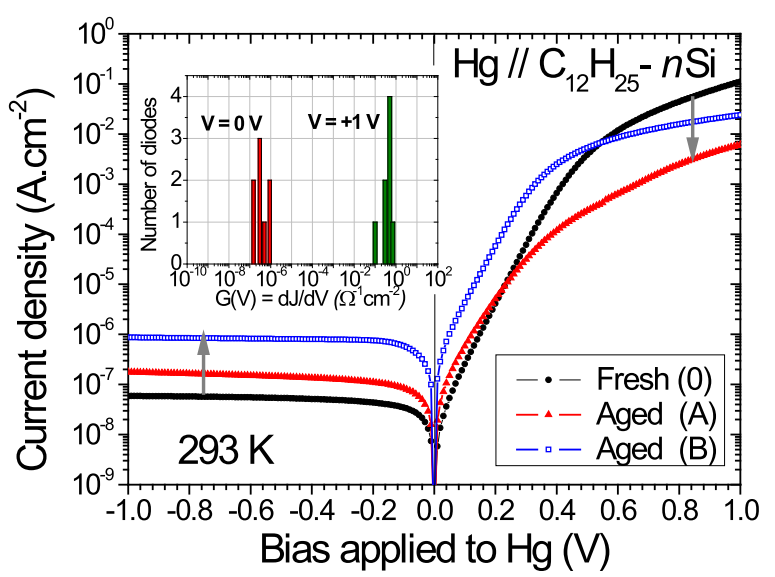

FIG. 3. Current density $J(V)$ characteristics (293 K) of the $\mathrm{Hg} / / \mathrm{C}_{12} \mathrm{H}_{25}-n$-Si junction in the as-grafted state (0) and after ageing at points (A) and (B). Inset: distribution of conductance values in the as-grafted state in depletion $(0 \mathrm{~V})$ and accumulation $(+1 \mathrm{~V})$. 


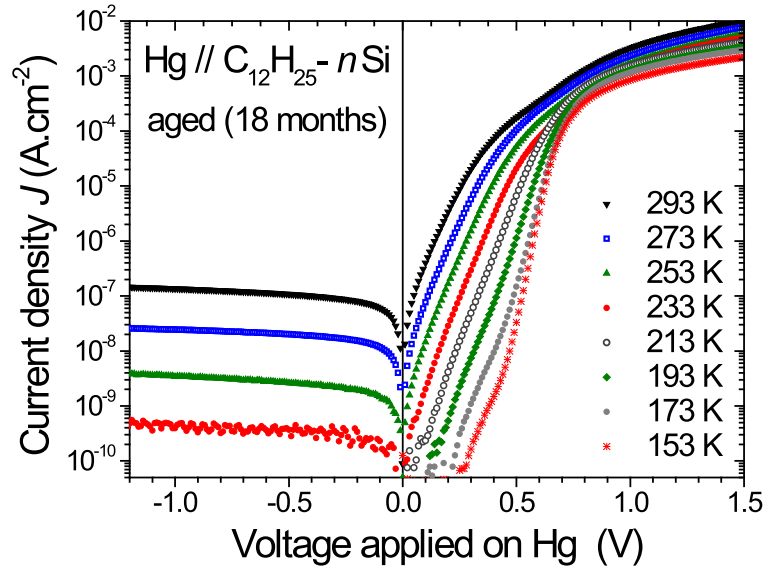

FIG. 4. Temperature dependence of $J(V)$ characteristics for the $\mathrm{Hg} / /$ $\mathrm{C}_{12} \mathrm{H}_{25}-n$-Si junction after ageing (point $\mathrm{A}$ ).

$\left(R=J_{\mathrm{FWD}}(V) / J_{\mathrm{REV}}(-V)>10^{6}\right.$ at $\left.\pm 1 \mathrm{~V}, 293 \mathrm{~K}\right)$ and the large value of the apparent ideality factor $(n=1.45$ at $293 \mathrm{~K}$, increasing towards $n \approx 2$ at lower temperatures) (Fig. 3). The temperature dependence of $J(V)$ characteristics at low bias is described by a TE mechanism, above a barrier $\Phi_{B}$ with an ideality factor, $n$,

$$
\begin{aligned}
I(V)= & A^{*} S T^{2} \exp \left(-\beta^{0} d_{\mathrm{T}}\right) \exp \left(-q \Phi_{\mathrm{B}} / k T\right) \exp (q V / n k T) \\
& \times[1-\exp (-q V / k T)],
\end{aligned}
$$

where $A^{*}$ is the Richardson constant $\left(A^{*}=112 \mathrm{~A} \mathrm{~cm}^{-2} \mathrm{~K}^{-2}\right.$ for $n$-type $\mathrm{Si}$ ), $q$ the electron charge, $k$ the Boltzmann constant, $T$ the temperature, and $S$ the $\mathrm{Hg}$ drop contact area. Here, $\beta^{0}=2\left(2 m^{*} \Phi_{\mathrm{T}} / \hbar^{2}\right)^{\frac{1}{2}}$ is the inverse attenuation length at zero applied bias, $\hbar$ the reduced Planck's constant, and $m^{*}$ the effective mass of electrical carriers in the OML. The effective barrier height, $\Phi_{\mathrm{EFF}}$, is derived in the forward bias range where $J(V)$ is exponential, typically $0.15-0.35 \mathrm{~V}$ above $243 \mathrm{~K}$, and $0.25-0.45 \mathrm{~V}$ below $173 \mathrm{~K}$. Above $243 \mathrm{~K}, \Phi_{\mathrm{EFF}}(T)$ follows a linear T-dependence ("0" data in Fig. 5); analysis neglecting any barrier height distribution (Eq. (1)), provides values of $\beta^{0} d_{\mathrm{T}}=13.5 \pm 0.2$ and $q \Phi_{\mathrm{B}}=0.53 \pm 0.05 \mathrm{eV}$ in the as-grafted state. ${ }^{32}$

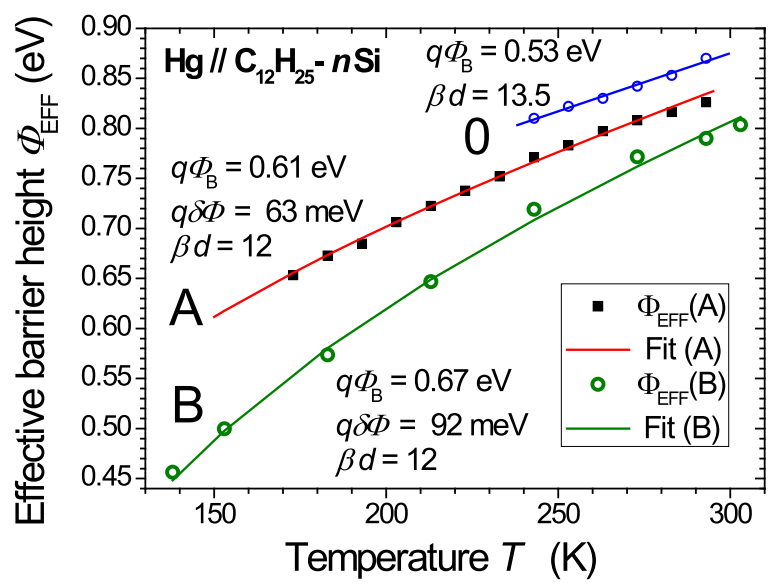

FIG. 5. Effective barrier height (symbols) derived from the exponential part of $J(V)$ at low forward bias, and fitting of $\Phi_{\mathrm{B}}, \beta^{0} d_{\mathrm{T}}$, and $\delta \Phi$ (Eq. (4)) to $\Phi_{\mathrm{EFF}}(T)$ data. Equation (1) has been used for the as-grown state (0).
At high forward bias $(V>0.6 \mathrm{~V})$, saturation in $J(V)$ and weak temperature dependence of $J(T)$ indicate that the current becomes limited either by the TB or by some contact resistance, rather than by the TE barrier inside the semiconductor. In addition, current limitation in the high forward bias range, near $1.5 \mathrm{~V}$, indicates that the series resistance increases with decreasing temperature (Fig. 4). This behavior is typical of rectifying $\mathrm{Hg} / / \mathrm{OML}-n$-type Si MIS tunnel junctions investigated previously. ${ }^{18,23,24}$

Fig. 3 shows that ageing in air results in a strong modification of the $J(V)$ characteristics at $293 \mathrm{~K}$ : (a) the forward bias current in the tunnel regime $(0.6-1.0 \mathrm{~V})$ has decreased by more than one decade (point A), as expected for a thicker tunnel barrier due to the $\mathrm{SiO}_{2}$ interface; (b) the exponential current in the TE regime $(0.0-0.5 \mathrm{~V})$ is strongly bent with an increasing apparent ideality factor; and (c) the reverse bias current has increased by a factor of 20 (point B).

At low temperatures (Fig. 4), $J(V)$ characteristics clearly reveal an excess current, as compared with the theoretical thermionic emission current with a single barrier height. A quantitative analysis in terms of a barrier height distribution (Figs. 5 and 6), responsible for a high apparent ideality factor, will be discussed in Sec. IV.

\section{AC electrical transport}

The band bending in the semiconductor and the Schottky barrier height can also be derived from a Mott-Schottky plot of the junction capacitance, since a linear dependence of
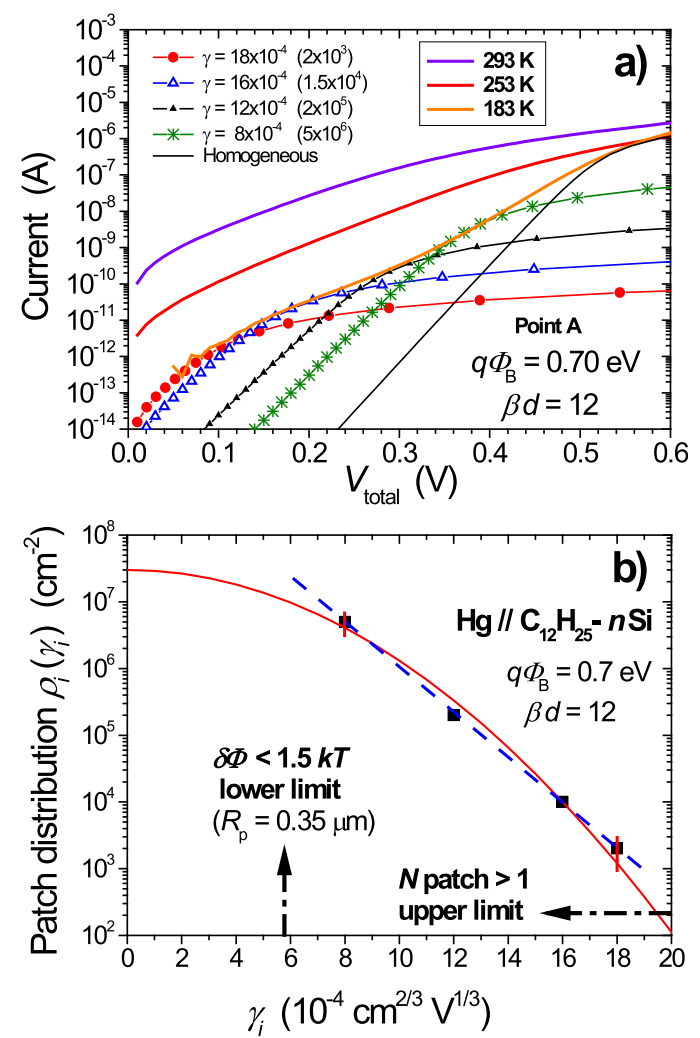

FIG. 6. (a) Experimental $J(V)$ at low forward bias after ageing (point A: $183 \mathrm{~K}$, $253 \mathrm{~K}$, and $293 \mathrm{~K}$ ) and simulation of $J(V)$ data at $183 \mathrm{~K}$ using $R_{\mathrm{S}}=50 \Omega \mathrm{cm}^{2}$, $S=5 \times 10^{-3} \mathrm{~cm}^{2}, q \Phi_{\mathrm{B}}=0.7 \mathrm{eV}, \beta^{0} d_{\mathrm{T}}=12, n=1$, and the distribution $\rho_{\mathrm{i}}\left(\gamma_{\mathrm{i}}\right)$ shown by squares in (b). 
$C^{-2}$ vs $V$ is expected when the space charge layer capacitance is much smaller than the insulator capacitance, $C_{\mathrm{i}}$. The flat band voltage of the $\mathrm{Hg} / / \mathrm{C}_{12} \mathrm{H}_{25}-n \mathrm{Si}$ junction, obtained as the $V$-axis intercept (at high frequency, $1 \mathrm{MHz}$ to $100 \mathrm{kHz}$, not shown), decreases from $V_{\mathrm{FB}}=0.68 \pm 0.03 \mathrm{~V}$ in the asgrafted state to smaller values $(0.62 \mathrm{~V}$ and $0.30 \mathrm{~V}$ for points $\mathrm{A}$ and $\mathrm{B}$, respectively) for the aged junction.

Immediately after grafting, no capacitance hysteresis is observed in a cyclic voltage scan, from $0 \mathrm{~V}$ to $-4 \mathrm{~V}$ (depletion) to $+0.8 \mathrm{~V}$ (accumulation near flat band conditions) to $0 \mathrm{~V}^{32}$ After ageing, hysteresis appears at low frequencies, below 10 $\mathrm{Hz}$, in the forward bias range (not shown). The capacitance at reverse bias $(V<0 \mathrm{~V})$ is low, $C_{\mathrm{REV}}=10-20 \mathrm{pF}\left(2-4 \mathrm{nF} \mathrm{cm}^{-2}\right)$, at all frequencies, showing the formation of a depletion layer.

Complex admittance $Y^{*}(\omega)=G+j \omega C$ (for a parallel R$\mathrm{C}$ circuit) as a function of the angular frequency, $\omega=2 \pi f$, may also be analyzed using the complex electrical modulus $M^{*}=\left(\varepsilon^{*}\right)^{-1}$, which conveniently provides peaks in the imaginary modulus, $M^{*}(\omega)$, at the characteristic device frequencies. ${ }^{32}$ Low temperature admittance reveals two bias dependent peaks (Fig. 7) and one bias-independent response (discussed in Sec. V B).

Two bias dependent peaks are expected from a kinetic modelling of the MIS tunnel diode, based on kinetic equations for a non equilibrium junction, as reported elsewhere; ${ }^{34}$ in a first approximation, $f_{1}=(G / 2 \pi C)$ and $f_{2}=(1 / 2 \pi \tau)$ correspond, respectively, to the space charge layer barrier and to the tunnel barrier characteristic frequencies. The model shows that both intensity and frequency of $M^{*}(\omega)$ peaks are influenced by the dc current density and the density of interface states, $D_{\mathrm{S}}$, in the $\mathrm{Si}$ band gap.

Experimentally, the $f_{1}$ peak frequency increases with applied bias; at $173 \mathrm{~K}$, it appears only in the forward bias regime where $G$ becomes large enough; it has a large maximum peak value ( $M^{\prime \prime}$ MAX), which decreases with increasing bias because the $C$ value increases. In contrast, the $f_{2}$ peak is not seen in our experiments although its intensity should be

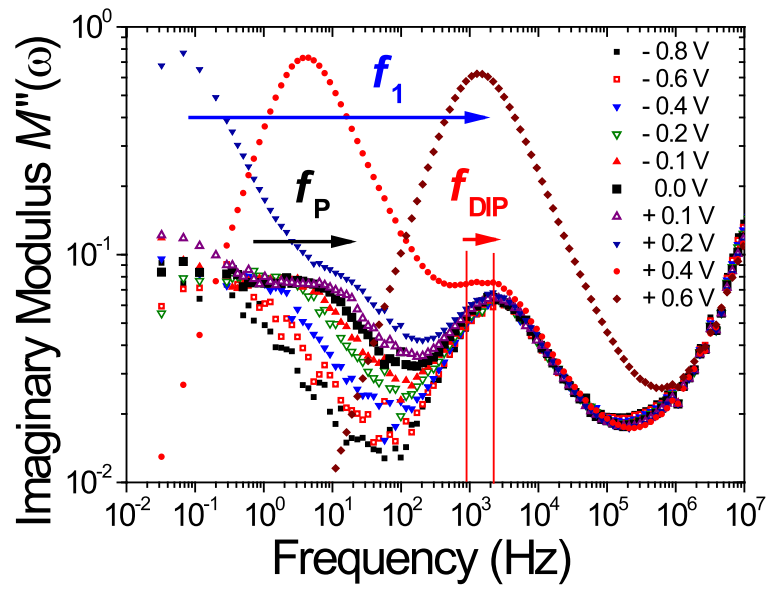

FIG. 7. Bias dependence of the imaginary electrical modulus $M^{\prime \prime}(\omega)$ at $173 \mathrm{~K}$ (point A) showing three resonances: (i) a main peak, strongly biasdependent, related to the semiconductor space charge region, with characteristic frequency $f_{1}=\mathrm{G} / 2 \pi C$, (ii) a small peak, weakly bias-dependent, possibly related to the patch response $\left(f_{\mathrm{P}}\right)$, (iii) a small peak, bias-independent, related to the dipolar relaxation, with characteristic frequency $f_{\mathrm{DIP}} \approx 2 \mathrm{kHz}$. The increase above $0.3 \mathrm{MHz}$ is due to the series resistance. large for a high density of interface states in the aged state; it might not be observed if $\tau<10^{-7} \mathrm{~s}$. The small bias dependent response at low frequency $\left(f_{\mathrm{P}}\right)$ could result from some modulation of the patch current through modulation of position and height of the saddle point in front of the low interface barrier; this hypothesis is supported by the broad character of this low frequency response.

In the aged state, Fig. 7 also reveals an additional weak peak near $2 \mathrm{kHz}$, which remains independent of applied bias over a broad range, from $-0.8 \mathrm{~V}$ to $+0.4 \mathrm{~V}$. This peak frequency $f_{\text {DIP }}$ has a very small temperature dependence, less than a factor of 3 in the range $134-193 \mathrm{~K}$, as depicted by the red arrow in Fig. 7; this corresponds to a typical activation energy $E_{\mathrm{ACT}} \approx 0.04 \mathrm{eV}$. As discussed below, this component is tentatively attributed to dipolar relaxation of some molecular moieties and labeled as $f_{\text {DIP. }}$

A different representation of the admittance data has been proposed recently; ${ }^{34}$ it consists in plotting the low frequency "excess" capacitance, arbitrarily defined as $C_{\mathrm{LF}}$ $(100 \mathrm{~Hz})-C_{\mathrm{HF}}(1 \mathrm{MHz})$, as a function of the dc current density (Fig. 8, point A, cyclic scan). Here, $C_{\mathrm{HF}}$ is the space charge layer capacitance, Csc. In the depletion regime (low forward bias, low current density), the interface states are unable to respond to the ac bias modulation, and the dipolar relaxation capacitance is essentially observed; being biasindependent, it appears as a plateau. This plateau in the dipolar relaxation capacitance of the $\mathrm{Hg} / / \mathrm{C}_{12} \mathrm{H}_{25}-\mathrm{Si}$ junction increases by a factor of 40 after ageing (Fig. 8, dashed arrow). In contrast, as the forward applied bias is increased, the response of interface states above midgap is increasingly observed and $\left(C_{\mathrm{LF}}-C_{\mathrm{HF}}\right)$ exceeds the plateau value. An increase from 60 to $600 \mathrm{nF} \mathrm{cm}{ }^{-2}$ is observed after ageing of the $\mathrm{Hg} / / \mathrm{C}_{12} \mathrm{H}_{25}-\mathrm{Si}$ junction (Fig. 8, full line arrow); the corresponding value of the density of states near mid gap increases from $D_{\mathrm{S}} \approx 5 \times 10^{10} \mathrm{eV}^{-1} \mathrm{~cm}^{-2}$ in the as-grafted state to $D_{\mathrm{S}} \approx 5 \times 10^{11} \mathrm{eV}^{-1} \mathrm{~cm}^{-2}$ after ageing. This increase in the interface states response by a factor $\approx 10$ can be

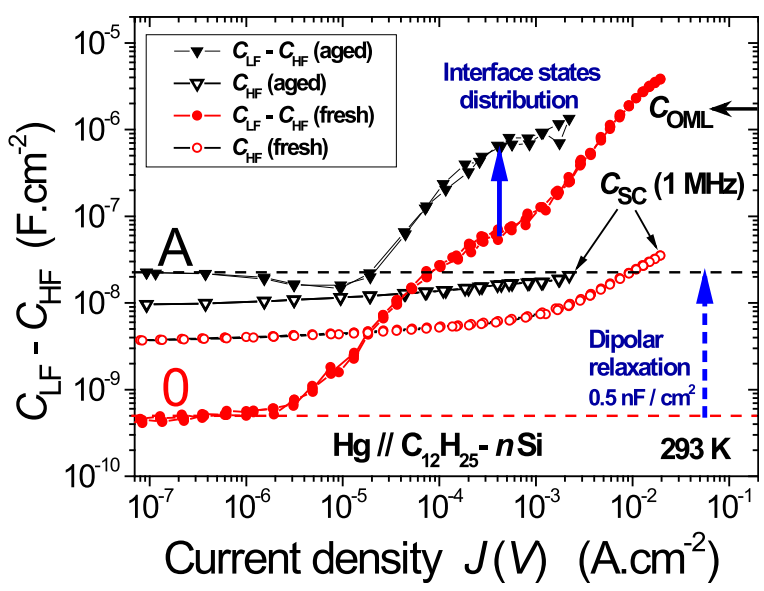

FIG. 8. Excess low frequency capacitance, $C_{\mathrm{LF}}(100 \mathrm{~Hz})-C_{\mathrm{HF}}(1 \mathrm{MHz})$, and semiconductor capacitance $\left(C_{\mathrm{HF}}\right)$ as a function of the dc current density $J(V)$ through the $\mathrm{Hg} / / \mathrm{C}_{12} \mathrm{H}_{25}-n$-Si junction in the as-grown state (0) and after ageing (point $\mathrm{A})$. In the as-grafted state, the measured $C_{\mathrm{LF}}$ exceeds the calculated insulator capacitance $C_{\mathrm{OML}} \cdot{ }^{34}$ The dipolar relaxation plateau increases by a factor $\times 40$ (dashed line arrow) and the response of localized states increases by a factor $\times 10$ (full line arrow). 
attributed either to some desorption of hydrogen at $\mathrm{Si}-\mathrm{H}$ surface sites or to the defective interface oxide layer. It is emphasized that a low dipolar contribution is an important condition to detect a small surface states response, since the latter may be masked by any dipolar relaxation of interface or embedded polar moieties.

\section{CURRENT DENSITY ANALYSIS}

The temperature dependence of effective barrier values, derived in the $\mathrm{TE}$ regime $(\mathrm{V}<+0.4 \mathrm{~V})$, qualitatively confirms an increasing contribution of low barrier height patches to the total current as temperature decreases, as shown by the steeper slope in $q \Phi_{\mathrm{EFF}}(T)$, which is observed at low $\mathrm{T}$ (Fig. 5). In the following, two quantitative methods differing by the treatment of the "pinch off" effect are proposed to obtain the distribution of low effective barrier patches, responsible for the excess current in $J(V, T)$ characteristics.

\section{A. Gaussian distribution with no "pinch off” (model A)}

Model A neglects "pinch off" effects (an assumption valid for large patch area). The patches are thus independent, and the current is the sum of $I(V)$ characteristics corresponding to the $\Phi_{\mathrm{EFF}}$ distribution. Assuming a Gaussian distribution, $P\left(\Phi_{\mathrm{EFF}}\right) \approx \exp \left[-\left(\left(\Phi_{\mathrm{B}}-\Phi_{\mathrm{EFF}}\right) / \sqrt{2} \delta \Phi\right)^{2}\right]$, of barrier heights, with a standard deviation $\delta \Phi$, the integrated current flow is thus dominated by patches with an effective barrier height $^{55,60}$

$$
q \Phi_{\mathrm{EFF}}(T)=q \Phi_{\mathrm{B}}+(k T) \beta^{0} d_{\mathrm{T}}-(q \delta \Phi)^{2} / 2 k T .
$$

The barrier height deduced from $J(V)$ measurements is always smaller than the average value, $q \Phi_{\mathrm{B}}+(k T) \beta^{0} d_{\mathrm{T}}$, and this departure is larger at lower temperatures. Typical values for the effective barrier lowering, $(q \delta \Phi)^{2} / 2 k T=0.05-0.20 \mathrm{eV}$, are expected at ambient temperature for $q \delta \Phi$ values in the 50-100 meV range.

Since this model provides an analytical temperature dependence, Eq. (4) allows fitting of the standard deviation, $\delta \Phi$, and tunnel barrier attenuation factor $\left(\beta^{0} d_{\mathrm{T}}\right)$ using effective barrier values $q \Phi_{\mathrm{EFF}}(T)$ obtained over a wide temperature range (Fig. 5). Since the exponential $J(V)$ range is quite narrow (in particular at point $\mathrm{A}$ ), large error bars arise in the $q \Phi_{\mathrm{EFF}}(T)$ values at high temperature, which may affect the fit results; hence in this work, the value of $\left(\beta^{0} d_{\mathrm{T}}\right)$ was constrained to be the same for points $\mathrm{A}$ and $\mathrm{B}$. The homogeneous barrier height, $q \Phi_{\mathrm{B}}$, is slightly larger at point $\mathrm{B}$; however the main difference (relevant to describe the $J(V)$ shape) arises from a wider distribution at point $\mathrm{B}$, $q \delta \Phi=92 \pm 4 \mathrm{meV}$, as compared to the standard deviation at point $\mathrm{A}, q \delta \Phi=63 \pm 4 \mathrm{meV}$.

\section{B. Arbitrary distribution of $\gamma$ values with "pinch off" (model B)}

In the case of a real interface including small patches with "pinch off" effects, the effective patch area and the effective barrier both depend on the applied potential through $\gamma$ and $V_{\mathrm{bb}}$. Taking into account the series resistance effect, the current through a single patch is given by

$$
\begin{aligned}
I_{\mathrm{PATCH}}(V)= & A^{*} T^{2}\left(\frac{4 \pi \gamma \eta^{2 / 3} k T}{9 q V_{\mathrm{bb}}^{2 / 3}}\right) \exp \left(-\beta^{0} d_{\mathrm{T}}\right) \\
& \times \exp \left(-q \Phi_{\mathrm{B}}^{\mathrm{HOM}} / k T\right) \exp \left(\frac{q \gamma V_{\mathrm{bb}}^{1 / 3}}{\eta^{1 / 3} k T}\right) \\
& \times[\exp (q V / k T)-1],
\end{aligned}
$$

where $V=V_{\mathrm{a}}-R_{S} I_{\text {PATCH }}$ is smaller than the applied bias, $V_{\mathrm{a}}$. An arbitrary distribution of $\gamma$ parameter values for circular patches can be derived from $J(V)$ data at the lowest accessible temperature, which provides the best sensitivity to the high $\gamma$ patches. ${ }^{56,57}$ This distribution must also describe $J(V)$ characteristics at higher $T$, by adjusting only the series resistance $R_{\mathrm{S}}(T)$. In this study, it is found that $R_{\mathrm{S}}$ increases with decreasing temperature, from $2 \Omega \mathrm{cm}^{2}$ at $293 \mathrm{~K}$ to $50 \Omega \mathrm{cm}^{2}$ at $183 \mathrm{~K}$.

Using $J(V)$ data at $T=183 \mathrm{~K}$ and setting $R_{\mathrm{S}}=50 \Omega \mathrm{cm}^{2}$ to describe the bias range above $0.5 \mathrm{~V}$, Fig. 6 (a) shows that a limited number of $\gamma$ values, in the range $8-18 \times 10^{-4} \mathrm{~cm}^{2 / 3}$ $\mathrm{V}^{1 / 3}$, is sufficient to obtain an envelope function which accurately reproduces the measured current; with the addition of the homogeneous current, the matching is correct over six decades. Note that for large $\gamma$ patches (high current density), the current saturation with applied bias is due to the voltage drop on the series resistance or spreading resistance. Hence, as shown in Figure 6(a), at a given bias, the current is dominated by a narrow range of $\gamma$ values, i.e., increasing forward bias selectively probes patches with smaller $\gamma$ values.

The upper limit for statistically significant $\gamma$ values (Fig. 6(b)) is defined by the condition $\rho_{\mathrm{i}}\left(\gamma_{\mathrm{i}}\right) S \gg 1$, while the lower limit is dependent on the measurement temperature. Within error bars, the corresponding distribution of $\gamma$ values, $\rho_{\mathrm{i}}\left(\gamma_{\mathrm{i}}\right)$ shown in Fig. 6(b)), can be described either by a Gaussian function (full red line) with standard deviation $\delta \gamma=4 \times 10^{-4}$ $\mathrm{cm}^{2 / 3} \mathrm{~V}^{1 / 3}$ or by an exponential function (dashed blue line) with inverse slope $\gamma^{0}=1.3 \times 10^{-4} \mathrm{~cm}^{2 / 3} \mathrm{~V}^{1 / 3}$.

\section{DISCUSSION}

Comparative analysis of electrical transport characteristics of $\mathrm{Hg} / / \mathrm{C}_{12} \mathrm{H}_{25}-n \mathrm{Si}$ junctions in the ac and dc modes, before and after ageing at the ambient, reveals local oxidation effects in the dipolar relaxation at the molecular scale and in the effective barrier height distribution. The physical origin of interface potential fluctuations may arise from some inhomogeneous distribution of dipoles, charge transfer, or charged defects; ${ }^{76}$ in molecular junctions, interface oxidation decreases the barrier height at the semiconductor interface, as reported in previous works. ${ }^{26,49}$

\section{A. Interface oxidation}

As shown previously, ${ }^{24,44,49}$ the oxidation kinetics of the $\mathrm{C}_{12} \mathrm{H}_{25}-n \mathrm{Si}$ interface is slow, with a 2 months typical time scale, in contrast with a few hours time scale for the oxidation of hydrogenated $\mathrm{Si}(111): \mathrm{H}$ surfaces. It is thus expected 
that ageing at the ambient for 18 months should produce a strongly oxidized $\mathrm{C}_{12} \mathrm{H}_{25}-n \mathrm{Si}$ interface.

XPS shows a $\mathrm{SiO}_{2}$ component at the $\mathrm{C}_{12} \mathrm{H}_{25}-n$ Si interface corresponding to an average thickness of $0.17 \mathrm{~nm}$; inhomogeneous oxidation requires that interface oxide thickness has locally larger values. The thickness of this $\mathrm{SiO}_{2}$ layer is thus important as compared with the OML tunnel barrier thickness, $d_{\mathrm{OML}}=1.45 \mathrm{~nm}$. As depicted in Fig. 1, the density of adventitious $\mathrm{OH}$ and strongly physisorbed $\mathrm{H}_{2} \mathrm{O}$ molecules is comparable to the density of oxidized $\mathrm{Si}$ atoms and is twice the density of grafted dodecyl molecules. These figures are important for the discussion of dipolar relaxation at the molecular scale.

Capacitance measurements using a liquid electrode suggest that water molecules can penetrate through molecular monolayers with low packing density; for long-term passivation of $\mathrm{Si}$ with $n$-alkyl molecules, a threshold coverage of $3.2 \times 10^{14} \mathrm{~cm}^{-2}$ has been calculated corresponding to intermolecular channels narrower than $0.28 \mathrm{~nm}$, which is equal to the diameter of a water molecule. ${ }^{71}$ Similarly, recent studies using a $\mathrm{Hg}$ top metal contact ${ }^{33}$ have shown a reversible effect of hydration/annealing at $150^{\circ} \mathrm{C}$ on the conductance and low frequency capacitance of alkyl $/ n$-type $\mathrm{Si}$ junctions. This effect is nearly negligible if the molecular monolayer is closely packed. In this study, the $\mathrm{C}_{12}$ molecular layer coverage being smaller than the threshold value of $3.2 \times 10^{14} \mathrm{~cm}^{-2}$, water molecule penetration may occur at specific locations with low packing density where Si oxidation is also expected.

\section{B. Dipolar relaxation at the molecular scale}

Complementary information on the OML structure is given by the dynamic properties of the $\mathrm{Hg} / / \mathrm{C}_{12} \mathrm{H}_{25}-n \mathrm{Si}$ junction, investigated at low temperatures and reverse applied bias to minimize the dc conductance response of the junction which would otherwise mask the dipolar relaxation. ${ }^{28}$ After ageing, admittance data clearly reveal a relaxation peak at a characteristic frequency $f_{\mathrm{DIP}} \approx 2 \mathrm{kHz}$, independent of applied bias and band bending in the semiconductor. Its intensity is much stronger in the aged $\mathrm{Hg} / / \mathrm{C}_{12} \mathrm{H}_{25}-n \mathrm{Si}$ junction $\left(M^{\prime \prime}{ }_{\mathrm{MAX}} \approx 0.06\right)$ than in the as-grafted device $\left(M^{\prime \prime}{ }_{\text {MAX }} \ll 0.01\right.$, not shown). For these two reasons, the response at $f_{\mathrm{DIP}}=2 \mathrm{kHz}$ is attributed to dipolar relaxation of some molecular moieties, arising at or near the silicon oxide interface. In the following, two physical origins consistent with literature data are discussed for the dipolar relaxation observed near $2 \mathrm{kHz}$ : (a) relaxation of a C-C bond dipole in the alkyl chain next to silicon oxide and (b) physisorbed $\mathrm{H}_{2} \mathrm{O}$ molecular relaxation.

A small dipolar relaxation effect is expected in the asgrafted junction, due to the small value of the alkyl chain permanent dipole perpendicular to the interface ${ }^{13}$ and with the small number of dipoles $\left(\approx 1 \times 10^{12}\right.$ molecules $)$ in the junction.

In recent literature, dipolar relaxation at similar frequency values (near $1 \mathrm{kHz}$ ) were also found at low temperature in $n$-alkyl-dimethylchlorosilane $\left(\mathrm{C}_{4}\right.$ to $\left.\mathrm{C}_{18}\right)$ self-assembled monolayers (SAMs) grafted on fused silica substrates with interdigitated electrodes $(235 \mathrm{~K})^{77}$ and in $n$-alkyl-trichlorosilane $\left(\mathrm{C}_{10}\right.$ and $\left.\mathrm{C}_{18}\right)$ SAMs immobilized on porous glass pow- ders $(160 \mathrm{~K}) .^{78}$ In both cases, a significant decrease in frequency with increasing molecular coverage was reported and attributed to structural ordering. In similar experiments, no interface component was observed for a reference $\mathrm{Hg} / /$ $\mathrm{SiO}_{2}(3 \mathrm{~nm})-n \mathrm{Si}$ junction with no monolayer; ${ }^{28}$ in addition, for this frequency window, the $\mathrm{SiO}_{2}$ response is expected below $100 \mathrm{~K}^{77}$

Hence, a likely origin of dipolar relaxation at $f_{\mathrm{DIP}} \approx 2 \mathrm{kHz}$ could be some relaxation of a $\mathrm{C}-\mathrm{C}$ bond dipole in the alkyl chain next to silicon oxide. It has been suggested ${ }^{78}$ that a strong polar bond in $\mathrm{SiO}_{2}$ may induce a weaker dipole in the first segments of the alkyl chain near the molecule-substrate interface. This was confirmed by the observation of similar dielectric relaxation in both polar (explicit permanent dipole) and nonpolar (only induced dipole near a siloxane linkage) molecular layers. ${ }^{77}$ This hypothesis could explain the increased intensity of the dipolar relaxation after ageing of the $\mathrm{C}_{12} \mathrm{H}_{25}-n \mathrm{Si}$ interface; however, in this work, the dipolar peak frequency $f_{\mathrm{DIP}}$ has a very small temperature dependence, with an activation energy $E_{\mathrm{ACT}} \approx 0.04 \mathrm{eV}$, much smaller than $E_{\mathrm{ACT}} \approx 0.25 \mathrm{eV}$, observed for $n$-alkyl-trichlorosilane SAMs on porous glass. ${ }^{78}$ This very small activation energy indicates that local motion of short segments ( $\beta$ relaxation) rather than large amplitude motion of an entire molecule could be involved in the dipolar relaxation at $f_{\mathrm{DIP}}=2 \mathrm{kHz}$.

As an alternative explanation, relaxation of water molecules, adsorbed preferentially at the oxidized interface regions, cannot be excluded, and this mechanism could compete with the induction effect of $\mathrm{Si}-\mathrm{O}$ bond dipole in the first segments of the alkyl chain near the molecule-substrate interface. Indeed, a dipolar relaxation at $1 \mathrm{kHz}$ has been found near $200 \mathrm{~K}$ for confined glassy water condensed on various surfaces: it has been attributed to a local $\beta$-like relaxation process of water molecules interacting with the host material. ${ }^{79}$

\section{Distribution of interface barrier heights}

Modifications of dc electrical transport characteristics observed after ageing are attributed to the oxidation observed by XPS; they are well described by an effective barrier height distribution. In the thermionic emission regime, a distribution of low effective barrier patches qualitatively explains the excess current at reverse and low forward bias and the discrepancy between barrier heights derived from capacitance and saturation current. A distribution of barrier heights explains both the bias-dependence of the ideality factor and the apparent discrepancy between a large ideality factor value $(n=1.46$ at $293 \mathrm{~K})$ and a small density of interface states $\left(D_{\mathrm{S}}<10^{11} \mathrm{eV}^{-1} \mathrm{~cm}^{-2}\right)$ obtained in the same bias range, as found for the as-grafted device. ${ }^{32}$ Note that incorporation of device inhomogeneity is crucial for an accurate modeling of $J-V$ characteristics, otherwise artificially large interface defect densities may be required to account for the large values of the apparent ideality factor. ${ }^{80}$

The lateral spatial extension of the low barrier height regions can be estimated from the distribution of $\gamma$ values, derived in the framework of the patch model, which considers that the smaller low barrier height patches are "pinched off." In the limited range of $\gamma$ values, $8-18 \times 10^{-4} \mathrm{~cm}^{2 / 3} \mathrm{~V}^{1 / 3}$, used 
to describe experimental transport data, the corresponding typical patch radius $R_{P}$ values are expected between 0.2 and $0.5 \mu \mathrm{m}$ (setting arbitrarily $\Delta_{P} \approx 0.3 \mathrm{eV}$ ), which is consistent with the requirements of the dipole approximation, i.e., $R_{P}$ is smaller than the width of the space charge layer $W=\left(2 V_{b b} \eta\right)^{1 / 2}$, with $\eta=\left(\varepsilon_{S} / q N_{D}\right)=4.4 \times 10^{-8} \mathrm{~cm}^{2} \mathrm{~V}^{-1}$, as long as the band bending $V_{b b}=\Phi_{\mathrm{B}}-V-V_{n}$ is larger than $30 \mathrm{mV}$.

The distribution of $\gamma$ values, $\rho_{\mathrm{i}}\left(\gamma_{\mathrm{i}}\right)$, can be equally well described either by a Gaussian function or by an exponential function (Fig. 6(b)). A comparison can be made between the standard deviation $\delta \Phi=63 \mathrm{meV}$ of model A (Eq. (4)) and the standard deviation $\delta \gamma=4 \times 10^{-4} \mathrm{~cm}^{2 / 3} \mathrm{~V}^{1 / 3}$ derived from model B (Fig. 6(b)) since ${ }^{60}$

$$
\delta \Phi=\delta \gamma\left(\frac{V_{b b}}{\eta}\right)^{1 / 3}
$$

This expression indicates that methods $\mathrm{A}$ and $\mathrm{B}$ do not probe exactly the same part of the distribution since $V_{b b}$ is biasdependent. The fitted parameters $\delta \Phi$ and $\delta \gamma$ are consistent with $V_{b b} \approx 0.2 \mathrm{~V}$, which defines some average band bending at low applied voltage.

The homogeneous barrier height $(0.7 \mathrm{eV})$ chosen for simulation of $J(V)$ at $T=183 \mathrm{~K}$ based on model B (Fig. 6(a)) is intermediate between the average barrier obtained from Mott-Schottky plots near room temperature $(0.90 \mathrm{eV})$ and model A analysis over the full temperature range $(0.61 \mathrm{eV})$. Since the total space charge of an inhomogeneous junction is not affected by details of the band bending at the interface, the barrier height value, $\Phi_{B}^{C V}$, derived from a Mott-Schottky plot of the reverse bias capacitance, is the average of the distribution of barrier heights. If the analysis of the saturation current of $J(V, T)$ obtained in the forward bias regime, using Eq. (4), is correct then the equality $\Phi_{B}^{C V}=\Phi_{B}^{J V}$ is expected. At point B, $q \Phi_{B}^{C V}-q \Phi_{B}^{J V}=-0.07 \mathrm{eV}$ (at $293 \mathrm{~K}$ ) is within error bars but at point $\mathrm{A}$, the difference $q \Phi_{B}^{C V}-q \Phi_{B}^{J V}=0.3 \mathrm{eV}$ (at $293 \mathrm{~K}$ ) is significantly high. This could indicate some limits in the rough model A, which neglects "pinch off" effects. In contrast, model B considers the bias dependence of both interface potential modulation and patch area variations, which combine into a $\gamma$ parameter distribution.

Finally, in spite of its limitations, the Gaussian distribution model (Eq. (4)) remains useful because it shows that neglecting the distribution of interface potential may lead to overestimate the $q \Phi_{\mathrm{EFF}}(T)$ slope and hence the tunnel parameter, $\beta^{0} d_{\mathrm{T}}$, value, in particular at low temperatures. Using Eq. (1) near $300 \mathrm{~K}$ would lead to a typical overestimation of $\beta^{0} d_{\mathrm{T}}$ of about 3 and 6 for the $q \delta \Phi$ parameters derived, respectively, at points $\mathrm{A}(q \delta \Phi=63 \mathrm{meV})$ and $\mathrm{B}(q \delta \Phi=92 \mathrm{meV})$. An acceptable error in $\beta^{0} d_{\mathrm{T}} \approx 1$ (i.e., an error smaller than $0.7 \mathrm{~nm}^{-1}$ in the $\beta^{0}$ value) requires a very homogeneous tunnel barrier with $q \delta \Phi<36 \mathrm{meV}$. This condition $(q \delta \Phi<1.5 \mathrm{kT})$ sets a lower limit on experimentally accessible $\gamma$ values (Fig. 6(b)) typically $6 \times 10^{-4} \mathrm{~cm}^{2 / 3} \mathrm{~V}^{1 / 3}$ (using $R_{\mathrm{P}}=0.35 \mu \mathrm{m}$ ).

Using the optical OML thickness $\left(d_{\mathrm{T}}=1.45 \mathrm{~nm}\right)$ and neglecting image force effects, it is found that the attenuation parameter value, $\beta^{0}=0.83 \pm 0.1 \AA^{-1}$, is consistent with $\beta^{0} \approx 0.87 \pm 0.1 \AA^{-1}$ in $\mathrm{Hg} / /$ alkanethiol - Ag junctions ${ }^{81}$ but it is slightly higher than $\beta^{0} \approx 0.65 \AA^{-1}$ in junctions with a covalent $\mathrm{Si}-\mathrm{C}$ bonded interface on $n$-type $\mathrm{Si}$ deduced from the variable molecular length method. ${ }^{18}$

\section{Charge transfer effect on interface barrier heights}

Oxidation of the $\mathrm{Si}$ interface contributes to a strong increase of the conductance in the reverse bias regime; in this work, this observation has been attributed to a broadening of the Schottky barrier distribution, which was quantitatively described by the patch model (Sec. V C). Although it does not consider minority carrier transport, this model captures most of electrical transport features over a broad temperature range.

At this point, it cannot be decided whether $\mathrm{SiO}_{2}$ formation alone is able to decrease the interface potential or some additional contribution of physisorbed water also occurs. Contact potential difference measurements combined with XPS analysis under ambient pressure have shown that water molecules can be adsorbed on oxidized silicon with a significant increase of the contact potential (net positive charge or dipole on the surface) of about $400 \mathrm{meV}$, which essentially occurs between 2 and 5 water monolayers. ${ }^{51}$ This result shows that $\mathrm{H}_{2} \mathrm{O}$ vapor adsorption can significantly decrease the barrier height in oxidized patches.

In addition, the role of water molecule adsorption at the OML/Si interface has been suggested to explain hydration/ annealing experiments performed on $\mathrm{Hg} / / \mathrm{OML}-n \mathrm{Si}$ junctions, showing a reversible change of both dc current density and low frequency capacitance. ${ }^{33}$ The reversible increase in dc current density is consistent with the above picture; however, it is not clear if localized interface states are created by some kind of water related complexes, or if the observed increase in low frequency capacitance is simply the result of increased current density, as predicted by recent modeling of MIS tunnel diode applied to hybrid molecular junctions in the forward bias regime. ${ }^{34}$

Finally, redox transfer from a semiconductor to a physisorbed water layer has been extensively discussed in another context, namely the high surface conductance of diamond films due to hole accumulation upon exposure to moist air. ${ }^{50}$ Modeling of the SC/water interface including the $\mathrm{H}_{2} / 2 \mathrm{H}^{+}$redox couple allows prediction of electron transfer for various semiconductors. ${ }^{50}$ The potential of the $\mathrm{H}_{2} \mathrm{O} / 2 \mathrm{H}^{+}$redox couple being above the Fermi level of silicon, ${ }^{33}$ the thin water layer can act as a surface electron donor for the OML/Si system; hence, the electron exchange from the water layer to silicon, governed by the redox reaction $2 \mathrm{H}_{2} \mathrm{O}+\mathrm{H}_{2} \rightarrow 2 \mathrm{H}_{3} \mathrm{O}^{+}$ $+2 \mathrm{e}^{-}$, may contribute to decrease both the positive space charge inside the semiconductor and the upward band bending.

\section{CONCLUSION}

The role of monolayer quality has been addressed through a comparison of the temperature dependence of electron transport over a wide temperature range, before and after ageing in air. Admittance and current density characteristics of rectifying $\mathrm{Hg} / / \mathrm{C}_{12} \mathrm{H}_{25}-n$ Si junctions incorporating $n$-alkyl molecular layers covalently bonded to $\mathrm{Si}(111)$ reveal local oxidation effects both at the submicron scale in the effective barrier 
height distribution and at the molecular scale in the dipolar relaxation measured at low temperature. Other sources of device inhomogeneity (non uniformity in OML thickness and induced density of states, top electrode oxidation) are expected to be more weakly affected than $\mathrm{Si}$ interface oxidation.

In the thermionic emission regime, a distribution of barrier heights qualitatively explains the excess current, the large apparent ideality factor, and the discrepancy between barrier heights derived from capacitance and saturation current. Fitting low temperature dc current density $J(V, T)$ characteristics with an arbitrary distribution of patch parameters (model B including "pinch-off") provides a narrow range of $\gamma$ values, which is equally well described by Gaussian or exponential functions. Neglecting "pinch-off" effects, model A has the advantage of an analytical temperature dependence of the effective barrier height (Eq. (4)), which allows a simple separation of energetic (barrier height, $q \Phi_{\mathrm{B}}$ and standard deviation, $\delta \Phi$ ) and kinetic (tunnel attenuation parameter $\left.\beta^{0} d_{\mathrm{T}}\right)$ properties of the junction.

Incorporation of device inhomogeneity is crucial to accurate modeling of $J-V$ characteristics, otherwise very large interface defect densities are required to account for the large values of the apparent ideality factor. Actually, ultrathin MIS tunnel barriers can be considered as homogeneous if $q \delta \Phi<1.5 \mathrm{kT}$, which allows using Eq. (1) near room temperature to determine the tunnel barrier transparency.

The slow buildup of an interface silicon oxide layer observed after ageing also brings a significant increase in the mid gap density of states, which typically rises to the high $10^{11} \mathrm{eV}^{-1} \mathrm{~cm}^{-2}$ range, after 18 months ageing at the ambient. The bias-independent relaxation observed near $1 \mathrm{kHz}$ at low temperature may be attributed either to dipoles in the alkyl chain induced by the strong permanent dipoles of interface silicon oxide and/or to a local relaxation of water molecules trapped at the OML/silicon interface. The respective roles of $\mathrm{SiO}_{2}$ formation and water physisorption in the decrease of the patch barrier height have been discussed. More work with intentional oxidation of the silicon substrate or controlled density of dipoles embedded in the molecule backbone will be necessary to discriminate both mechanisms.

\section{ACKNOWLEDGMENTS}

Bruno Fabre and Cyril Herrier (CNRS-University of Rennes 1) are gratefully acknowledged for molecular device synthesis. We also wish to thank Cristelle Mériadec for some XPS characterizations. This work was funded by Région Bretagne and Rennes Métropole.

${ }^{1}$ D. K. Aswal, S. Lenfant, D. Guerin, J. V. Yakhimi, and D. Vuillaume, Anal. Chim. Acta 568, 84 (2006).

${ }^{2}$ E. J. Faber, L. C. P. M. de Smet, W. Olthuis, H. Zuilhof, E. J. R. Sudholter, P. Bergveld, and A. Van den Berg, Chem. Phys. Chem. 6, 2153 (2005).

${ }^{3}$ S. M. Lindsay and M. A. Ratner, Adv. Mater. 19, 23 (2007).

${ }^{4}$ D. Vuillaume, C.R. Phys. 9, 78 (2008).

${ }^{5}$ A. Vilan, O. Yaffe, A. Biller, A. Salomon, A. Kahn, and D. Cahen, Adv. Mater. 22, 140-159 (2010).

${ }^{6} \mathrm{~A}$. W. Ghosh, Comprehensive Semiconductor Science and Technology (Elsevier, Amsterdam, 2011), Chap. 5.09, pp. 383-479.

${ }^{7}$ M. R. Linford and C. E. D. Chidsey, J. Am. Chem. Soc. 115, 12631 (1993).
${ }^{8}$ C. L. McGuiness, D. Blasini, J. P. Masejewski, S. Uppili, O. M. Cabarcos, D. Smilgies, and D. L. Allara. ACS Nano 1, 30 (2007).

${ }^{9}$ S. Szunerits and R. Boukherroub, J. Solid State Electrochem. 12, 1205 (2008).

${ }^{10}$ L. Scheres, M. Giesbers, and H. Zuilhof, Langmuir 26, 4790 (2010).

${ }^{11}$ A. Ulman, Chem. Rev. 96, 1533 (1996).

${ }^{12}$ P. Fenter, P. Eisenberger, and K. S. Liang, Phys. Rev. Lett. 70, 2447 (1993).

${ }^{13}$ S. Pleutin, N. Clement, D. Guerin, and D. Vuillaume, Phys. Rev. B 82, 125436 (2010).

${ }^{14}$ G. Gannon, J. C. Greer, J. A. Larsson, and D. Thompson, ACS Nano 4, 921 (2010).

${ }^{15}$ Y. Selzer, A. Salomon, and D. Cahen, J. Phys. Chem. B 106, 10432 (2002).

${ }^{16}$ Y. L. Liu and H. Z. Yu, J. Phys. Chem. B 107, 7803 (2003).

${ }^{17}$ C. Miramond and D. Vuillaume, J. Appl. Phys. 96, 1529 (2004).

${ }^{18}$ A. Salomon, T. Boecking, C. K. Chan, F. Amy, O. Girshevitz, D. Cahen, and A. Kahn, Phys. Rev. Lett. 95, 266807 (2005).

${ }^{19}$ O. Seitz, T. Boecking, A. Salomon, J. J. Gooding, and D. Cahen, Langmuir 22, 6915 (2006).

${ }^{20}$ L. Segev, A. Salomon, A. Natan, D. Cahen, L. Kronik, F. Amy, C. K. Chan, and A. Kahn, Phys. Rev. B 74, 165323 (2006).

${ }^{21}$ N. Clement, S. Pleutin, O. Seitz, S. Lenfant, and D. Vuillaume, Phys. Rev. B 76, 205407 (2007).

${ }^{22}$ A. Vilan, J. Phys. Chem. C 111, 4431 (2007).

${ }^{23}$ A. Salomon, T. Boecking, O. Seitz, T. Markus, F. Amy, C. K. Chan, W. Zhao, D. Cahen, and A. Kahn, Adv. Mater. 19, 445 (2007).

${ }^{24}$ S. Maldonado, K. E. Plass, D. Knapp, and N. S. Lewis, J. Phys. Chem. C 111, 17690 (2007).

${ }^{25}$ M. Furuhashi, A. Omura, Y. Yamashita, K. Mukai, J. Yoshinobu, K. Akagi, and S. Tsuneyuki, Jpn. J. Appl. Phys. 48, 055003 (2009).

${ }^{26}$ O. Yaffe, L. Scheres, S. R. Puniredd, N. Stein, A. Biller, R. H. Lavan, H. Shpaisman, H. Zuilhof, H. Haick, D. Cahen, and A. Vilan, Nano Lett. 9, 2390 (2009).

${ }^{27}$ O. Yaffe, L. Scheres, L. Segev, A. Biller, I. Ron, E. Salomon, M. Giesbers, A. Kahn, L. Kronik, H. Zuilhof, A. Vilan, and D. Cahen, J. Phys. Chem. C 114, 10270 (2010).

${ }^{28}$ N. Clement, S. Pleutin, D. Guerin, and D. Vuillaume, Phys. Rev. B 82, 035404 (2010).

${ }^{29}$ C. Godet, A. Fadjie, S. Ababou-Girard, and F. Solal, Appl. Phys. Lett. 97, 132105 (2010).

${ }^{30}$ I. Tasçioglu, U. Aydemir, and S. Altindal, J. Appl. Phys. 108, 064506 (2010).

${ }^{31}$ M. M. Thuo, W. F. Reus, C. A. Nijhuis, J. R. Barber, C. Kim, M. D. Schulz, and G. M. Whitesides, J. Am. Chem. Soc. 133, 2962 (2011).

${ }^{32}$ A. B. Fadjie-Djomkam, S. Ababou-Girard, R. Hiremath, C. Herrier, B. Fabre, F. Solal, and C. Godet, J. Appl. Phys. 110, 083708 (2011).

${ }^{33}$ N. Clement, D. Guerin, S. Pleutin, S. Godey, and D. Vuillaume, J. Phys. Chem. C 116, 17753 (2012).

${ }^{34}$ C. Godet, A. B. Fadjie-Djomkam, and S. Ababou-Girard, "Effect of high current density on the admittance response of interface states in ultrathin MIS tunnel junctions," Solid State Electron. (to be published).

${ }^{35}$ T. Frederiksen, C. Munuera, C. Ocoal, M. Branbyge, M. Paulsson, D. Sanchez-Portal, and A. Arnau, ACS Nano 3, 2073 (2009).

${ }^{36}$ S. Guo, J. Hihath, I. Diez-Perez, and N. Tao, J. Am. Chem. Soc. 133, 19189 (2011).

${ }^{37}$ K. Smaali, N. Clement, G. Patriarche, and D. Vuillaume, ACS Nano 6, 4639 (2012).

${ }^{38}$ W. J. Royea, A. Juang, and N. S. Lewis, Appl. Phys. Lett. 77, 1988 (2000).

${ }^{39}$ D. Michalak and N. S. Lewis, Appl. Phys. Lett. 80, 4458 (2002).

${ }^{40}$ A. Lehner, F. Kohl, S. A. Franzke, T. Graf, M. S. Brandt, and M. Stutzmann, Appl. Phys. Lett. 82, 565 (2003).

${ }^{41}$ A. B. Sieval, C. L. Huisman, A. Schonecker, F. M. Schuurmans, A. S. H. van der Heide, A. Goosens, W. C. Sinke, H. Zuilhof, and E. J. R. Sudholter, J. Phys. Chem. B 107, 6846 (2003).

${ }^{42}$ S. Kar, Appl. Surf. Sci. 252, 3961 (2006).

${ }^{43}$ M. R. Linford, P. Fenter, P. M. Eisenberger, and C. E. D. Chidsey, J. Am. Chem. Soc. 117, 3145 (1995).

${ }^{44}$ L. J. Webb and N. S. Lewis, J. Phys. Chem. B 107, 5404 (2003).

${ }^{45}$ R. Boukherroub, Curr. Opin. Solid State Mater. Sci. 9, 66 (2005).

${ }^{46}$ L. J. Webb, D. J. Michalak, J. S. Biteen et al., J. Phys. Chem. B 110, 23450 (2006).

${ }^{47}$ S. R. Puniredd, O. Assad, and H. Haick, J. Am. Chem. Soc. 130, 13727 (2008). 
${ }^{48}$ H. Sabbah, S. Ababou-Girard, A. Zebda, D. David, B. Fabre, S. Députier, A. Perrin, M. Guilloux-Viry, F. Solal, and C. Godet, Diamond Relat. Mater. 18, 1074 (2009).

${ }^{49}$ R. T. W. Popoff, H. Asanuma, and H. Z. Yu, J. Phys. Chem. C 114, 10866 (2010).

${ }^{50}$ F. Maier, M. Riedel, B. Mantel, J. Ristein, and L. Ley, Phys. Rev. Lett. 85, 3472 (2000).

${ }^{51}$ A. Verdaguer, C. Weis, G. Oncins, G. Ketteler, H. Bluhm, and M. Salmeron, Langmuir 23, 9699 (2007).

${ }^{52}$ P. L. Hanselaer, W. H. Laflere, R. L. Van Meirhaeghe, and F. Cardon, J. Appl. Phys. 56, 2309 (1984).

${ }^{53}$ D. R. Heslinga, H. H. Weitering, D. P. van der Werf, T. M. Klapwijk, and T. Hibma, Phys. Rev. Lett. 64, 1589 (1990).

${ }^{54}$ J. P. Sullivan, R. T. Tung, M. R. Pinto, and W. R. Graham, J. Appl. Phys. 70, 7403 (1991).

${ }^{55}$ J. H. Werner and H. H. Güttler, J. Appl. Phys. 69, 1522 (1991).

${ }^{56}$ R. T. Tung, Phys. Rev. B 45, 13509 (1992).

${ }^{57}$ P. Lahnor, K. Seiter, M. Schulz, W. Dorsch, and R. Scholz, Appl. Phys. A 61, 369 (1995)

${ }^{58}$ S. Chand and J. Kumar, J. Appl. Phys. 80, 288 (1996).

${ }^{59}$ R. F. Schmitsdorf and W. Mönch, Eur. Phys. J. B 7, 457 (1999).

${ }^{60}$ R. T. Tung, Mater. Sci. Eng. R 35, 1 (2001).

${ }^{61}$ S. Acar, S. Karadeniz, N. Tugluoglu, A. B. Selcuk, and M. Kasap, Appl. Surf. Sci. 233, 373 (2004).

${ }^{62}$ E. Ayyildiz, H. Cetin, and Z. J. Horvath, Appl. Surf. Sci. 252, 1153 (2005).

${ }^{63}$ I. Dokme, S. Altindal, and M. M. Bulbul, Appl. Surf. Sci. 252, 7749 (2006).

${ }^{64}$ A. Bengi, S. Altindal, S. Ozcelik, and T. S. Mammadov, Physica B 396, 22 (2007)
${ }^{65}$ G. Gomila and J. M. Rubi, J. Appl. Phys. 81, 2674 (1997).

${ }^{66}$ G. Gomila, J. Phys. D: Appl. Phys. 32, 64 (1999).

${ }^{67}$ C. J. Powell and A. Jablonski, NIST Electron Inelastic-Mean-Free-Path, Database version 1.1, 2000.

${ }^{68} \mathrm{X}$. Wallart, C. Henry de Villeneuve, and P. Allongue, J. Am. Chem. Soc. 127, 7871 (2005).

${ }^{69}$ M. P. Seah and S. J. Spencer, Surf. Interface Anal. 33, 640 (2002).

${ }^{70}$ E. H. Nicollian and J. R. Brews, MOS (Metal Oxide Semiconductor) Physics and Technology (Wiley, New York, 1982).

${ }^{71}$ P. Gorostiza, C. Henry de Villeneuve, Q. Y. Sun, F. Sanz, X. Wallart, R. Boukherroub, and P. Allongue, J. Phys. Chem. B 110, 5576 (2006).

${ }^{72}$ A. P. Grosvenor, B. A. Kobe, and N. S. McIntyre, Surf. Sci. 572, 217 (2004).

${ }^{73}$ J. W. He, X. Xu, J. S. Corneille, and D. W. Goodman, Surf. Sci. 279, 119 (1992).

${ }^{74}$ J. Finster, D. Schulze, F. Bechstedt, and A. Meisel, Surf. Sci. 152-153, 1063 (1985).

${ }^{75}$ K. Andersson, A. Gomez, C. Glover et al., Surf. Sci. 585, L183 (2005).

${ }^{76} \mathrm{~W}$. Mönch, Electronic properties of Semiconductor Interfaces (Springer, Berlin, 2004).

${ }^{77}$ M. C. Scott, D. R. Stevens, J. R. Bochinski, and L. I. Clarke, ACS Nano 2 , 2392 (2008).

${ }^{78}$ Q. Zhang, Q. Zhang, and L. A. Archer, J. Phys. Chem. B 110, 4924 (2006).

${ }^{79}$ S. Cerveny, G. A. Schwartz, R. Bergman, and J. Swenson, Phys. Rev. Lett. 93, 245702 (2004).

${ }^{80}$ T. Toledano, A. Biller, T. Bendikov, H. Cohen, A. Vilan, and D. Cahen, J. Phys. Chem. C 116, 11434 (2012).

${ }^{81}$ R. E. Holmlin, R. Haag, M. L. Chabinyc et al., J. Am. Chem. Soc. 123, 5075-5085 (2001). 